\title{
Çamaltı Tuzlasının (Sasalı/izmir) alg florası ve mevsimsel değişimleri
}

\section{The seasonal changes and algal flora of Çamaltı Saltworks (Sasalı / İzmir)}

\author{
Edis Koru1* - Mustafa Deniz² \\ ${ }^{1}$ Ege Üniversitesi Su Ürünleri Fakültesi 35100, Bornova, İzmir \\ 2 İmir Kâtip Çelebi Üniversitesi Su Ürünleri Fakültesi Çiğli, İzmir \\ * Corresponding author: edis.koru@ege.edu.tr
}

\section{How to cite this paper:}

Koru, E. \& Deniz, M. (2017). The seasonal changes and algal flora of Çamaltı Saltworks (Sasalı / İzmir). Ege Journal of Fisheries and Aquatic Sciences, 34(4):431-442. doi: 10.12714/egejfas.2017.34.4.10

\begin{abstract}
Öz: Bu araşıłırma İmir Çamalıı tuzlası ekosisteminde dağılım gösteren alglerinin belirlenmesi amacıyla 2015 ylında, 8 istasyonda mevsimsel ve aylık örneklemeler yapılarak gerçekleştirilmiştir. Çalışma sonunda; Çamaltı tuzlası deniz alglerinden Cyanophyceae sınıfına ait 4, Chlorophyceae sınıfına ait 7, Bacillariophyceae 11 takson, Phaeophyceae sınıfına ait 3 takson, Rhodophyceae sınıfına ait 3 takson ve Monocots sınıfına ait 1 takson olmak üzere toplam 29 takson belirlenmişstir.
\end{abstract}

Anahtar kelimeler: Ege denizi, Çamaltı tuzlası, alg, Dunaliella, İmir, Türkiye

Abstract: This research was carried out in 2015 with the aim of determining the algae distributed in İmir Çamaltı saltworks ecosystem by making seasonal and monthly sampling in 8 stations. At the end of study; in total, 29 taxa including; 4 taxa belonging to Cyanophyceae class, 7 taxa including to Chlorophyceae class, 11 belonging to Bacillariophyceae class, 3 belonging to Phaeophyceae class, 3 taxa including to Rhodophyceae class and 1 taxa including to Monocots classis were determined.

Keywords: Aegean sea, Çamaltı Saltworks, Algae, Dunaliella, İzmir, Turkey

\section{Gíriş}

Sulak alanlar, yeryüzünün biyolojik, endüstriyel, sosyolojik olarak verimli ve en üretken ekosistemlerini oluşturmaktadır. Bu alanlar, yöre insanlarına ve ülkenin geneline geniş yelpazede (ekonomik, sosyolojik, kültürel, turizm vb.) hizmet veren oldukça karmaşık doğal sistemlerdir ve yeryüzündeki başka hiçbir ekosistemle karşılaştırılmayacak ölçüde işlev ve değerlere sahiptir. Türkiye'nin de taraf olduğu Ramsar Sözleşmesi'nde sulak alanların tanımı; "Doğal ya da yapay, sürekli ya da mevsimsel, tatlı, acı ya da tuzlu, durgun ya da akan su kütleleri, nehir ve göller, bataklıklar, turbalıklar ve gelgitin çekilmiş anında derinliği altı metreyi aşmayan deniz suları" olarak tanımlanmaktadır (Pritchard, 2010). Sulak alan kapsamında değerlendirilen yüksek tuzluluktaki kıyısal deniz tuzlaları, birincil üretim ve ekolojik özellikleri bakımından tüm Dünyada ve Akdeniz havzasındaki önemli biyolojik kaynaklardan bazılarıdır (Korovessis ve Lekkas, 2000: UNEP, 2013). Deniz kaynaklı Tuzlalar aynı zamanda mineral maden, su ürünleri, ekoturizm, rüzgâr ve güneş enerjisi, biyomas ve biyoteknolojik bakımından son derece önemli ekonomik potansiyele sahip ekosistemlerdir (Cheng, 1991; Borowitzka, 1997). Sulak alan özelliklerine sahip olan ve Gediz Deltası sınırları içerisinde bulunan İzmir Çamaltı Tuzlası, Gediz
Deltası'nın yaklaşık 20.400 km²'lik kısmının 1998 yılında Bakanlar Kurulu kararıyla Ramsar Sözleşmesi Listesi'ne dahil edilmesiyle "Uluslararası Öneme Sahip Sulak Alan" kapsamına alınmıştır. Ramsar statüsü dışında da bölgenin 1981 yılından beri 'Sit Alanı' statüsü bulunmaktadır. Oluşturulan "Sulak Alan Yönetim Planı" 2007 yılında tamamlanarak uygulamaya başlanmıştır. Ramsar Sözleşmesi kapsamındaki İzmir Çamaltı Tuzlası işletmesi $32.382 .000 \mathrm{~m}^{2}$ alandaki çeşitli hacimdeki buharlaştırma havuzları ve $3.148 .491 \mathrm{~m}^{2}$ alana yaygın 77-78 adet kristalizasyon havuzu ile İzmir Kuş Cennetiyle birlikte, Türkiye'nin önemli sulak alanlarından biridir. Aynı zamanda Türkiye'nin tuz intiyacının \%35-40'nı karşılayan, 2 adet deniz kaynaklı tuz üretim alanından, en büyük tek tuzlasıdır. Coğrafik olarak $38^{\circ} 30 \mathrm{dk}$. 18 sn. Kuzey, 26 54 dk. 55 sn. Doğu koordinatlarında, İzmir ili Sasalı beldesi, Çiğli ilçesindedir (Şekil $1)$.

Bu araştırmada, İzmir Çamaltı tuzlası ekosistemi kıyı littoral bölgeyle, tuz üretim parsellerindeki biyolojik (algler), fiziksel, kimyasal ve su kalite özelliklerinin belirlenmesi ve daha sonra yapılacak olan çalışmalarda kullanılmak üzere bir veri tabanı oluşturması amaçlanmıştır. 


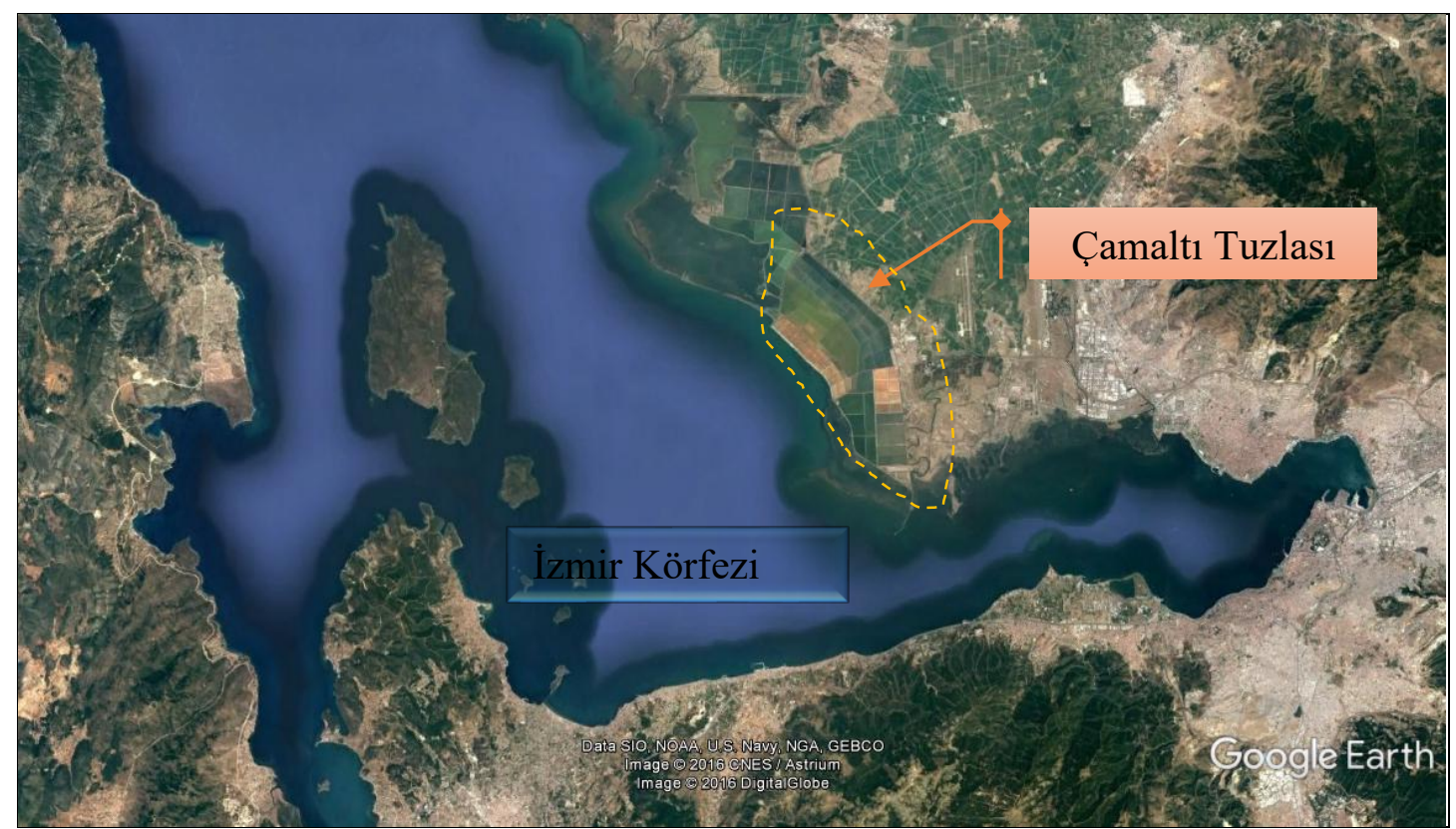

Şekil 1. Çamaltı tuzlası (Sasalı-lzzmir). (Google Earth, www.google.com/int//tr/earth/)

Figure 1. Çamaltı saltworks (Sasalı-Izmir). (Google Earth, www.google.com/int//tr/earth/)

\section{MATERYAL VE METOT}

\section{Çalışma alanı}

Çalışma, 2015 ylında, İzmir Çamalıı tuzlası ekosisteminde 8 istasyonda mevsimsel ve aylık örneklemelerle yürütülmüştür (Şekil 2).

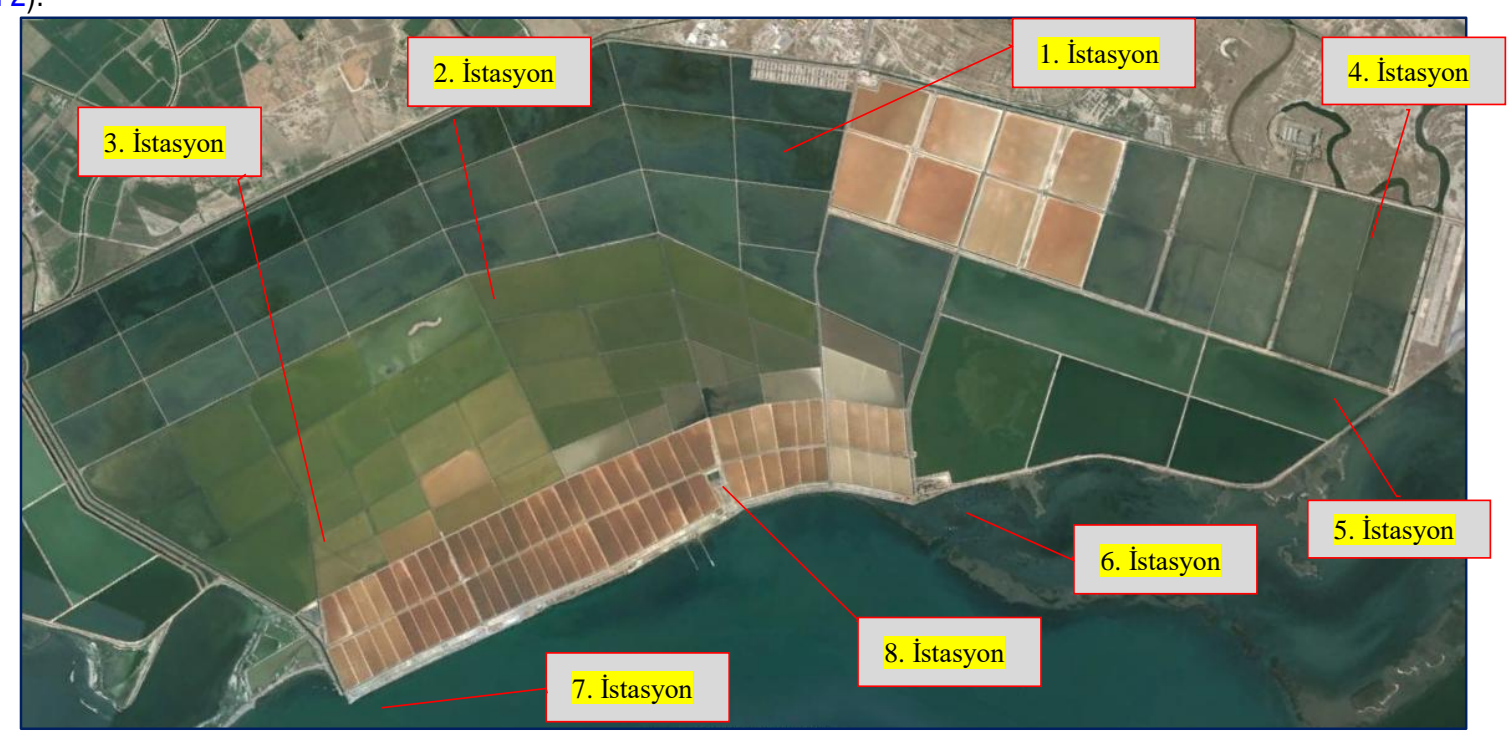

Şekil 2. İzmir Çamaltı Tuzlası ve örnekleme yapılan istasyonlar (Google Earth, https://www.google.com/int//tr/earth/) Figure 2. İzmir Çamaltı Saltworks and sampling stations (Google Earth, https://www.google.com/int//tr/earth/)

\section{Fitoplankton Örnekleme ve Teşhisi}

Ekosistemindeki fitoplankton tür çeşitliliğini ve yoğunluğunu belirlemek için her bir örnekleme havuzundan kıyı ve merkez olmak üzere iki noktadan çekim yapılarak, yüzey su filminin altından da $1 \mathrm{~L}$ su örneği alınmıştır. Laboratuvara getirilen örnekler I-KI (lügol) çözeltisi ilave edilerek $1 \mathrm{~L}$ hacme sahip cam mezürlerde 24 saat çöktürülmüş ve son hacim 100 ml'ye ayarlanarak saklanmıştır. Fitoplankton örneklerinin tür kompozisyonunu belirlemek için ise belirlenen istasyonlardan 
45um göz açıklığına sahip plankton kepçesiyle yüzeyden yatay çekim yapılarak örnek alınmıştır. Örnekler \%4'lük formaldehit solüsyonu ilave edilerek tespit edilmiştir. Alg taksonlarının tayininde Bourrelly (1968, 1970): Bourrelly ve Couté (1991); Hecky ve Kilham (1973); Oren (2005); Koray vd. (2007); Ak (2008); Nagasathya ve Thajuddin (2008); Yurga (2015) gibi araştırmacıların eserlerinden yararlanılmıştır.

Taksonların güncel isimleri ve sistematik kategorileri Algaebase, WoRMS (World Register Marine Species), LPSN (List of Prokaryotic names with standing in nomenclature) ve Plankweb (Check-list of Turkish Seas Microplankton) veri tabanından kontrol edilmiştir (Yurga, 2015). Taksonların nispi bolluk dereceleri belirlenmiş ve baskın $(\boldsymbol{\square})$, yarı baskın $(\boldsymbol{\Lambda})$ ve mevcut $(+)$ olarak sınıflandırılmıştır.

\section{Fiziksel Ölçümler}

Su sıcaklığı (T: $\left.{ }^{\circ} \mathrm{C}\right)$, toplam çözünmüş oksijen(mg/L), tuzluluk (S:ppt), pH gibi analitik değerler için HI98194 model multiparametre ölçüm cihazı ve Atago Brix 32 tuzluluk reflaktometresi, in situ olarak kullanılmıştır.

\section{Kimyasal Analizler}

Örnekleme istasyonlarından alınan su numunelerinin analizleri örneklemeyi izleyen ilk 24 saat içerisinde yapılmıştır. Analizlerde, Standarts Methods for the Examination of Water and Wastewater, American Public Health Association (APHA), metotları uygulanmıştır (APHA, 1992).

\section{BULGULAR}

\section{Biyolojik Bulgular}

Çamaltı tuzlası ekosisteminde 6 sınıfa ait 29 takson belirlenmiştir. Belirlenen taksonların 4 tanesi Cyanophyceae $(\% 13,79), 7$ tanesi Chlorophyceae (\%24,13), 11 tanesi Bacillariophyceae $(\% 37,93), 3$ tanesi Phaeophyceae $(\% 10,34)$, 3 tanesi Rhodophyceae $(\% 10,34), 1$ tanesi Monocots $(\% 3,44)$ sınıflarına aittir. Takson listesi Tablo 2'de verilmiştir. Ekosistemde en fazla takson sayısı Bacillariophyceae ve Chlorophyceae sınıflarına aittir. Bu sınifları sırasıyla Cyanophyceae, Rhodophyceae, Phaeophyceae ve tek tür ile Monocots takip etmektedir. Çamaltı tuzlası ekosisteminde 6 büyük alg sınıfına ait organizmaların aylık değişimi Tablo 1.'de verilmiştir.

Tablo 1. Çamaltı tuzlasında 2015 yılında tespit edilen algler ve aylara göre dağılımı (Taksonların nispi bolluk dereceleri; baskın (ロ), yarı baskın $(\boldsymbol{\Delta})$ ve mevcut (+) olarak ifade edilmiştir)

Table 1. The algae of Çamaltı saltworks and distribution by monthly in 2015 (Propotional abundance ratings of taxa expressed as; dominant (घ), semi-dominant $(\boldsymbol{\Lambda})$, and present $(+)$

\section{Zaman (2015 Yllı)}

$$
\text { Aylar }
$$

Ocak:(Ock): Şubat, (Şbt), Mart: (Mrt), Nisan: (Nsn), Mayıs: (Mys), Haziran: (Hzn), Temmuz: (Tmz), Ağustos: (Ats), Eylül: (Eyl), Ekim: (Ekm), Kasım: (Ksm), Aralık: (Ark) Örnekleme istasyonları: (1), (2), (3), (4), (5), (6), (7), (8).

\begin{tabular}{|c|c|c|c|c|c|c|c|c|c|c|c|c|}
\hline $\begin{array}{ll}\text { Taksonlar } & \text { Zaman } \\
\text { Cyanophyceae } & \\
\end{array}$ & Ock & Şbt & Mrt & Nsn & Mys & $\mathrm{Hzn}$ & $\operatorname{Tmz}$ & Ats & Eyl & Ekm & Ksm & Ark \\
\hline $\begin{array}{l}\text { Aphanothece halophytica } \\
\text { Frémy in Hof \& Frémy } \\
1933\end{array}$ & & & $\begin{array}{l}\text { (2) }+ \\
\text { (3) }+ \\
\text { (4) }+ \\
5+\end{array}$ & $\begin{array}{l}\text { (2) }+ \\
3+ \\
(4)+ \\
5+\end{array}$ & $\begin{array}{l}\text { (2) }+ \\
3+ \\
(3)+ \\
5+ \\
5+\end{array}$ & $\begin{array}{l}(2)+ \\
3+ \\
(4)+ \\
5+\end{array}$ & $\begin{array}{l}\text { (2) }+ \\
\text { (3) }+ \\
4+ \\
5+ \\
5+\end{array}$ & & & $\begin{array}{l}\text { (2) }+ \\
(3)+ \\
\text { (4) }+ \\
5+\end{array}$ & & \\
\hline $\begin{array}{l}\text { Lyngbya majuscuta C. } \\
\text { Agardh ex Gomont, } 1892\end{array}$ & $\begin{array}{l}\text { (1) } \\
\text { (2) }+ \\
\text { (6) }+ \\
(7)+\end{array}$ & $\begin{array}{l}(2)+ \\
(3)+\end{array}$ & $\begin{array}{l}(2)+ \\
(3)+\end{array}$ & $\begin{array}{l}(2)+ \\
(3)+\end{array}$ & (2) + & $\begin{array}{l}(2)+ \\
(3)+\end{array}$ & $\begin{array}{l}\text { (2) }+ \\
\text { (3) }+\end{array}$ & $\begin{array}{l}(2)+ \\
\text { (3) }+\end{array}$ & $\begin{array}{l}\text { (2) }+ \\
\text { (3) }+\end{array}$ & (2) + & (2)+ & (2) + \\
\hline $\begin{array}{l}\text { Oscillatoria sp. Vaucher ex } \\
\text { Gomont, } 1822\end{array}$ & $\begin{array}{l}\text { (2) }+ \\
\text { (3) }+\end{array}$ & & (2) + & $\begin{array}{l}\text { (3) }+ \\
6+ \\
\text { (7) }+\end{array}$ & $\begin{array}{l}\text { (3) }+ \\
6+ \\
\text { (7) }+\end{array}$ & (3) + & (3) + & (3) + & $\begin{array}{l}\text { (6)+ } \\
7+\end{array}$ & $\begin{array}{l}6+ \\
7+\end{array}$ & & \\
\hline $\begin{array}{l}\text { Halospirulina sp. Nübel et } \\
\text { al., } 2000\end{array}$ & (3) + & (3) + & (1) + & & & & & & & & & \\
\hline \multicolumn{13}{|l|}{ Chlorophyceae } \\
\hline $\begin{array}{l}\text { Dunaliella salina } \\
\text { Teodoresco, } 1905\end{array}$ & $\begin{array}{l}\text { (2)! } \\
\text { (3) } \\
\text { (4) } \\
\text { (5) }+ \\
\text { (8) }\end{array}$ & 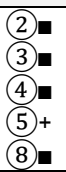 & $\begin{array}{l}\text { (2)! } \\
\text { (3)! } \\
\text { (4) } \\
\text { (5) }+ \\
\text { (8) }\end{array}$ & $\begin{array}{l}\text { (2)! } \\
\text { (3)! } \\
\text { (4) } \\
\text { (5) }+ \\
\text { (8) }\end{array}$ & $\begin{array}{l}\text { (2) } \\
\text { (3) } \\
\text { (4) } \\
\text { (5) }+ \\
\text { (8) }\end{array}$ & $\begin{array}{l}\text { (2) } \\
(3) \\
(4) \\
5 \\
(5) \\
(8)\end{array}$ & $\begin{array}{l}\text { (2) } \\
\text { (3) } \\
\text { (4) } \\
\text { (5) }+ \\
\text { (8) }\end{array}$ & $\begin{array}{l}\text { (2) } \\
\text { (3) } \\
\text { (4) } \\
\text { (5) }+ \\
\text { (8) }\end{array}$ & $\begin{array}{l}\text { (2) } \\
\text { (3) } \\
\text { (4) } \\
\text { (5) }+\end{array}$ & $\begin{array}{l}\text { (2) }= \\
\text { (3) } \\
\text { (4) }= \\
\text { (5) }+\end{array}$ & $\begin{array}{l}\text { (2)! } \\
\text { (3)! } \\
(4)- \\
55+ \\
\text { (8) }+\end{array}$ & $\begin{array}{l}\text { (2) } \\
\text { (3). } \\
\text { (4) } \\
\text { (5) }+ \\
(8)+\end{array}$ \\
\hline
\end{tabular}




\begin{tabular}{|c|c|c|c|c|c|c|c|c|c|c|c|c|}
\hline $\begin{array}{l}\text { Dunaliella viridis } \\
\text { Teodoresco, } 1905\end{array}$ & $\begin{array}{l}1 \\
\text { (2) } \mathbf{\Delta} \\
\text { (3) } \mathbf{A}\end{array}$ & $\begin{array}{l}1+ \\
(2) \Delta \\
(3)\end{array}$ & $\begin{array}{l}\text { (1) }+ \\
\text { (2) } \mathbf{\Delta} \\
\text { (3) } \Delta\end{array}$ & $\begin{array}{l}\text { (1) }+ \\
\text { (2) } \Delta \\
\text { (3) } \Delta\end{array}$ & $\begin{array}{l}1 \\
(2) \\
(3)\end{array}$ & (1) + & (1) + & (1) + & (1) + & (1) + & $\begin{array}{l}(1)+ \\
5+\end{array}$ & $\begin{array}{l}\text { (1) }+ \\
\text { (5) }+\end{array}$ \\
\hline Dunaliella sp. & $\begin{array}{l}1+ \\
\text { (2) } \\
\text { (3) } \\
\text { (4) } \\
5+\end{array}$ & $\begin{array}{l}\text { (1) }+ \\
\text { (2) }= \\
\text { (3) }= \\
\text { (4) }= \\
5+\end{array}$ & $\begin{array}{l}1+ \\
\text { (2) }= \\
\text { (3) }= \\
\text { (4) }= \\
5+\end{array}$ & $\begin{array}{l}\text { (1) }+ \\
\text { (2) } \\
\text { (3) } \\
\text { (4) } \\
5 \\
5\end{array}$ & $\begin{array}{l}\text { (1) }+ \\
\text { (2) }= \\
\text { (3) }= \\
\text { (4) }= \\
5+\end{array}$ & & & & & & (5) + & (5) + \\
\hline $\begin{array}{l}\text { Tetraselmis indica Arora } \\
\text { et.al.,2013. }\end{array}$ & & & & (2) + & $\begin{array}{l}(2)+ \\
(3)+\end{array}$ & $\begin{array}{l}(2)+ \\
(3)+\end{array}$ & (2) + & (2) + & & & & \\
\hline $\begin{array}{l}\text { Ulva rigida C. Agardh } \\
1823\end{array}$ & & & & (6) & $\begin{array}{l}\text { (6) } \\
\text { (7) }\end{array}$ & $\begin{array}{l}\text { (6) } \\
\text { (7) }\end{array}$ & (6) & $\begin{array}{l}\text { (6) } \\
\text { (7) }\end{array}$ & (6) & (6) & & \\
\hline $\begin{array}{l}\text { Chaetomorpha aerea } \\
\text { (Dillwyn) Kützing } 1849\end{array}$ & (1) & (1) & (1) & (1)! & & & & & (1) & (1) & (1)! & (1) \\
\hline $\begin{array}{l}\text { Enteromorpha intestinalis } \\
\text { (Linnaeus) Nees, } 1820\end{array}$ & (6) + & (6) + & (6) + & (6) + & (6) + & & & & & & & \\
\hline \multicolumn{13}{|l|}{ Bacillariophyceae } \\
\hline $\begin{array}{l}\text { Flagilaria sp. Lyngbye, } \\
1819,\end{array}$ & (1)+ & (1) + & (1) + & (1) + & & & & & & (1) + & (1) + & \\
\hline $\begin{array}{l}\text { Navicula sp. Bory de } \\
\text { Saint-Vincent, } 1822\end{array}$ & $\begin{array}{l}1+ \\
(2+\end{array}$ & $\begin{array}{l}\text { (1) }+ \\
(2)+\end{array}$ & $\begin{array}{l}\text { (1) }+ \\
\text { (2) }+\end{array}$ & $\begin{array}{l}\text { (1) }+ \\
(2)+\end{array}$ & $\begin{array}{l}1 \\
(2)+\end{array}$ & $\begin{array}{l}\text { (1) }+ \\
\text { (2) }+\end{array}$ & (1) + & (1) + & (1) + & (1) + & & \\
\hline $\begin{array}{l}\text { Closterium navicula } \\
\text { (Brébisson) Lütkemüller }\end{array}$ & $\begin{array}{l}1+ \\
(2)+\end{array}$ & $\begin{array}{l}1+ \\
(2+ \\
+\end{array}$ & $\begin{array}{l}1+ \\
(2)+\end{array}$ & $\begin{array}{l}1 \\
(2)+\end{array}$ & $\begin{array}{l}1+ \\
(2)+\end{array}$ & $\begin{array}{l}1 \\
(2)+\end{array}$ & & & & & & \\
\hline $\begin{array}{l}\text { Ceratoneis closterium } \\
\text { Ehrenberg } 1839\end{array}$ & $\begin{array}{l}1+ \\
4+ \\
5+\end{array}$ & & & & & & & $\begin{array}{l}(1)+ \\
(2)+\end{array}$ & & & & \\
\hline Chaetoceros affinis Lauder & & $\begin{array}{l}\text { (6) }+ \\
7+\end{array}$ & $\begin{array}{l}\text { (6) }+ \\
\text { (7) }+\end{array}$ & & & & & & & & & \\
\hline $\begin{array}{l}\text { Chaetoceros didymus } \\
\text { Ehrenberg }\end{array}$ & & $\begin{array}{l}\text { (6) }+ \\
(7)+\end{array}$ & (6) + & & & & & & & & & \\
\hline Gyrosigma sp. Hassall & (1) + & & & & & & & & & & & \\
\hline Gymnodinium sp. & & $\begin{array}{l}\text { (6) }+ \\
7+\end{array}$ & $\begin{array}{l}\text { (6) }+ \\
(7)+\end{array}$ & & & & & & & & & \\
\hline $\begin{array}{l}\text { Pleurosigma formosum W. } \\
\text { Smith } 1852\end{array}$ & (1) + & & & & & & & & & & & \\
\hline $\begin{array}{l}\text { Skeletonema costatum } \\
\text { (Greville) Cleve }\end{array}$ & & $\begin{array}{l}6+ \\
7+\end{array}$ & $\begin{array}{l}\text { (6) }+ \\
(7)+\end{array}$ & & & & & & & & & \\
\hline Thalassiosira sp. & & $\begin{array}{l}6+ \\
7+\end{array}$ & (6) + & & & & & & & & & \\
\hline \multicolumn{13}{|l|}{ Phaeophyceae } \\
\hline $\begin{array}{l}\text { Cystoseria barbata } \\
\text { (Stackhouse) C. } \\
\text { Agardh,1820 }\end{array}$ & $\begin{array}{l}\text { (6) }+ \\
7+\end{array}$ & $\begin{array}{l}\text { (6) }+ \\
7+\end{array}$ & $\begin{array}{l}\text { (6) }+ \\
\text { (7) }+\end{array}$ & $\begin{array}{l}\text { (6) }+ \\
\text { (7) }+\end{array}$ & $\begin{array}{l}\text { (6) }+ \\
7+\end{array}$ & $\begin{array}{l}\text { (6) }+ \\
\text { (7) }+\end{array}$ & $\begin{array}{l}\text { (6) }+ \\
\text { (7) }+\end{array}$ & $\begin{array}{l}\text { (6) }+ \\
\text { (7) }+\end{array}$ & $\begin{array}{l}\text { (6) }+ \\
\text { (7) }+\end{array}$ & $\begin{array}{l}\text { (6) }+ \\
7+\end{array}$ & $\begin{array}{l}\text { (6) }+ \\
\text { (7) }+\end{array}$ & $\begin{array}{l}\text { (6) }+ \\
\text { (7) }+\end{array}$ \\
\hline $\begin{array}{l}\text { Stypocaulon scoparium } \\
\text { (Linnaeus) Kützing }\end{array}$ & $\begin{array}{l}\text { (6) }+ \\
7+\end{array}$ & $\begin{array}{l}\text { (6) }+ \\
7+\end{array}$ & & & & & & & & & & $\begin{array}{l}\text { (6) }+ \\
(7)+\end{array}$ \\
\hline $\begin{array}{l}\text { Dictyota dichotoma } \\
\text { (Hudson) J.V. Lamouroux } \\
1809\end{array}$ & & $\begin{array}{l}\text { (6) }+ \\
7+\end{array}$ & $\begin{array}{l}\text { (6) }+ \\
\text { (7) }+\end{array}$ & & & & & & & & & $\begin{array}{l}\text { (6) }+ \\
\text { (7) }+\end{array}$ \\
\hline \multicolumn{13}{|l|}{ Rhodophyceae } \\
\hline $\begin{array}{l}\text { Gracilaria verrucosa } \\
\text { (Hudson) Papenfuss } 1950\end{array}$ & $\begin{array}{l}\text { (6) } \mathbf{\Delta} \\
\text { (7) } \Delta\end{array}$ & $\begin{array}{l}\text { (6) } \mathbf{\Delta} \\
\text { (7) } \mathbf{\Delta}\end{array}$ & $\begin{array}{l}\text { (6) } \Delta \\
\text { (7) } \Delta\end{array}$ & $\begin{array}{l}\text { (6) } \Delta \\
\text { (7) } \Delta\end{array}$ & $\begin{array}{l}\text { (6) } \mathbf{\Delta} \\
\text { (7) } \mathbf{\Delta}\end{array}$ & & & & & $\begin{array}{l}\text { (6) } \Delta \\
\text { (7) } \Delta\end{array}$ & $\begin{array}{l}\text { (6) } \Delta \\
\text { (7) } \Delta\end{array}$ & $\begin{array}{l}\text { (6) } \Delta \\
\text { (7) } \Delta\end{array}$ \\
\hline $\begin{array}{l}\text { Laurencia papillosa (C. } \\
\text { Agardh) Greville } 1830\end{array}$ & $\begin{array}{l}1 \\
\text { (2) }\end{array}$ & $\begin{array}{l}1 \\
2 \\
2\end{array}$ & $\begin{array}{l}1 \\
\text { (2) }\end{array}$ & 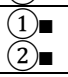 & $\begin{array}{l}1 \\
\text { (2) }\end{array}$ & $\begin{array}{l}\text { (1) } \\
(2)\end{array}$ & & & & $\begin{array}{l}1 \\
\text { (2) }\end{array}$ & (1) & $\begin{array}{l}\text { (1) } \\
\text { (2) }\end{array}$ \\
\hline $\begin{array}{l}\text { Hypnea sp. J.V. } \\
\text { Lamouroux, } 1813\end{array}$ & & & & & & $\begin{array}{l}\text { (6) }+ \\
(7)+\end{array}$ & $\begin{array}{l}\text { (6) }+ \\
(7)+\end{array}$ & $\begin{array}{l}\text { (6) }+ \\
(7)+\end{array}$ & $\begin{array}{l}\text { (6) }+ \\
\text { (7) }+\end{array}$ & & & \\
\hline \multicolumn{13}{|l|}{ Monocots } \\
\hline $\begin{array}{l}\text { Posidonia oceanica } \\
\text { (Linnaeus) Delile } 1813\end{array}$ & $\begin{array}{l}\text { (6) }+ \\
7+\end{array}$ & $\begin{array}{l}\text { (6) }+ \\
7+\end{array}$ & $\begin{array}{l}\text { (6) }+ \\
\text { (7) }+\end{array}$ & $\begin{array}{l}(6)+ \\
(7)+\end{array}$ & & & & & & & $\begin{array}{l}\text { (6) }+ \\
\text { (7) }+\end{array}$ & $\begin{array}{l}\text { (6) }+ \\
(7)+\end{array}$ \\
\hline
\end{tabular}

\section{Fiziksel ve Kimyasal Bulgular}

Çamaltı tuzlası ekosisteminde sıcaklık değerleri 9-30 ${ }^{\circ} \mathrm{C}$ arasında değişim göstermiştir. Sıcaklığa ait en yüksek değer
Ağustos 2015'de en düşük ise Ocak 2015 tarihinde ölçülmüştür. Çalışma süresince pH 7-8 arasında değişmiştir. pH' nın yillık ortalama değeri 8,01 olup en yüksek pH değeri 
Eylül 2015 tarihinde 1. istasyonda, en düşük ise Eylül 2015'de 2. istasyonda kaydedilmiştir. Çözünmüş oksijen konsantrasyonu gölde 0,2-9,1 mg/L arasinda olup yillık ortalama değeri 5,6 mg/L'dir. En yüksek çözünmüş oksijen konsantrasyonu Şubat 2015'de en düşük Temmuz-Ağustos 2015'de ölçülmüştür. Meteorolojik veriler Davis Vantage Pro2 ölçüm cihazı ile ölçülüp, Meteoroloji Genel Müdürlüğü verileriyle kıyaslanarak tespit edilmiştir (Tablo 2). Ekosistemde yapılan bazı fiziksel ölçümlere ve kimyasal analizlere ait sayısal veriler Şekil 3-6 ve Tablo 3 de sunulmuştur.

Tablo 2. Ege bölgesi (İzmir) Yıllık Mevsimsel İklim Değerleri (MGM, 2015. http://www.mgm.gov.tr/veridegerlendirme/il-ve-ilceleristatistik.aspx?m=|ZMIR\#sfB)

Table 2. Aegean Region (İzmir) Annual Seasonal Climate Values (MGM, 2015. http://www.mgm.gov.tr/veridegerlendirme/il-ve-ilceleristatistik.aspx?m=IZMIR\#sfB)

\begin{tabular}{|c|c|c|c|c|c|c|c|c|c|c|c|c|}
\hline IZMiR & Ocak & Şubat & Mart & Nisan & Mayıs & Haziran & Temmuz & Ağustos & Eylül & Ekim & Kasım & Aralık \\
\hline Zaman(yıl) & Yillar i & inde Ger & ekleşe & Ortalam & Değerle & (1950- 201 & & & & & & \\
\hline Ortalama Sıcaklık $\left({ }^{\circ} \mathrm{C}\right)$ & 8.9 & 9.5 & 11.7 & 15.9 & 20.8 & 25.6 & 28.0 & 27.7 & 23.7 & 18.8 & 14.0 & 10.6 \\
\hline $\begin{array}{l}\text { Ortalama En Yüksek } \\
\text { Sıcaklık }\left({ }^{\circ} \mathrm{C}\right)\end{array}$ & 12.5 & 13.5 & 16.3 & 20.9 & 26.0 & 30.7 & 33.2 & 32.9 & 29.1 & 23.9 & 18.5 & 14.1 \\
\hline $\begin{array}{l}\text { Ortalama En Düşük } \\
\text { Sıcaklık }\left({ }^{\circ} \mathrm{C}\right)\end{array}$ & 5.9 & 6.2 & 7.8 & 11.3 & 15.5 & 20.0 & 22.6 & 22.5 & 18.7 & 14.7 & 10.7 & 7.7 \\
\hline $\begin{array}{l}\text { Ortalama Güneşlenme } \\
\text { Süresi (saat) }\end{array}$ & 4.2 & 5.1 & 6.2 & 7.5 & 9.5 & 11.3 & 12.1 & 11.5 & 10.1 & 7.3 & 5.3 & 4.1 \\
\hline $\begin{array}{l}\text { Ortalama Yağışı Gün } \\
\text { Sayısı }\end{array}$ & 11.9 & 10.8 & 9.2 & 8.2 & 5.4 & 2.1 & 0.5 & 0.5 & 2.0 & 5.6 & 8.9 & 12.5 \\
\hline $\begin{array}{l}\text { Aylık Toplam Yağış } \\
\text { Miktarı Ortalaması }\left(\mathbf{k g} / \mathrm{m}^{2}\right)\end{array}$ & 125.1 & 101.9 & 75.6 & 46.4 & 30.9 & 9.8 & 1.8 & 2.6 & 15.0 & 45.3 & 94.8 & 141.1 \\
\hline
\end{tabular}

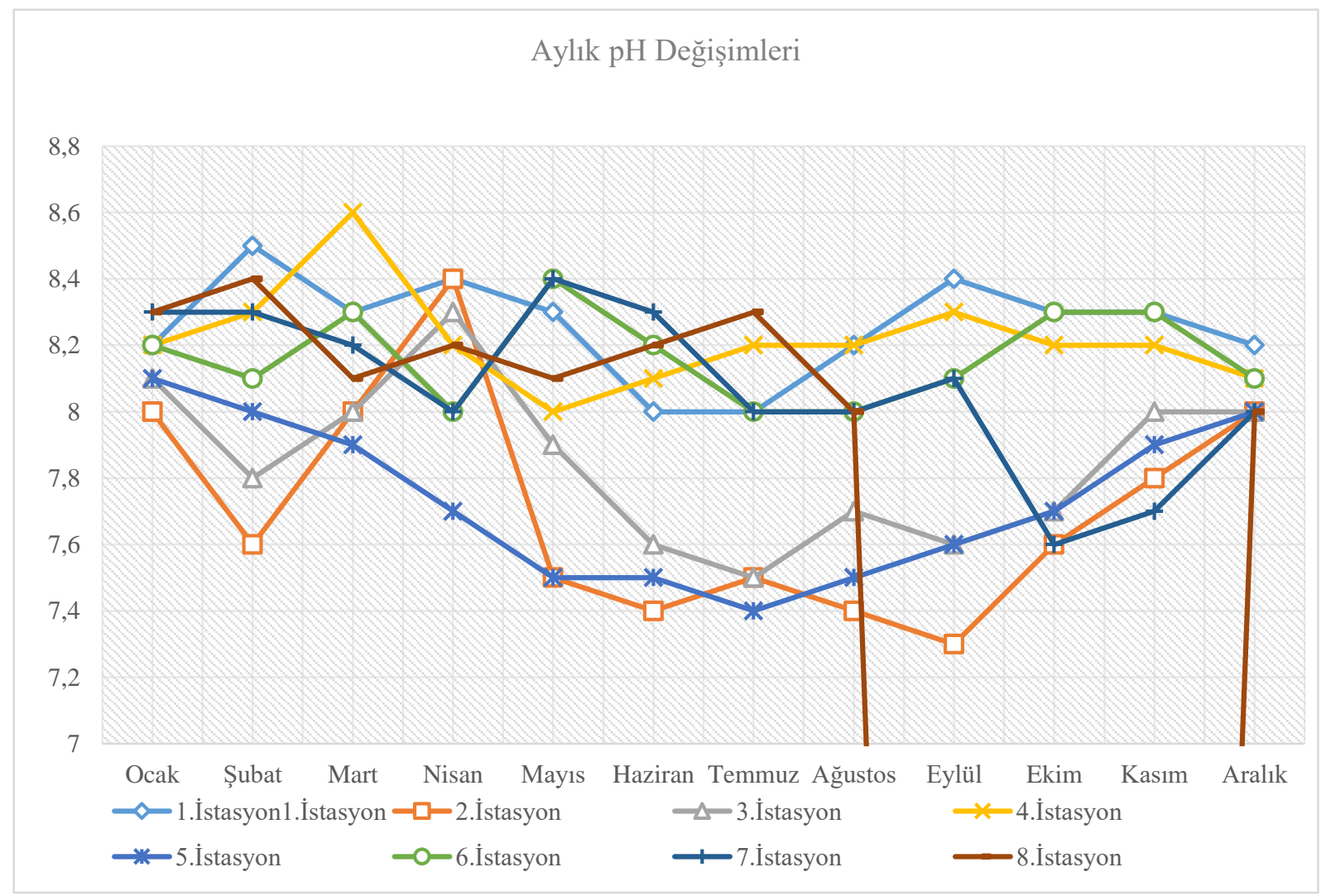

Şekil 3. Aylık pH değişimleri

Figure 3. Monthly $\mathrm{pH}$ changes 


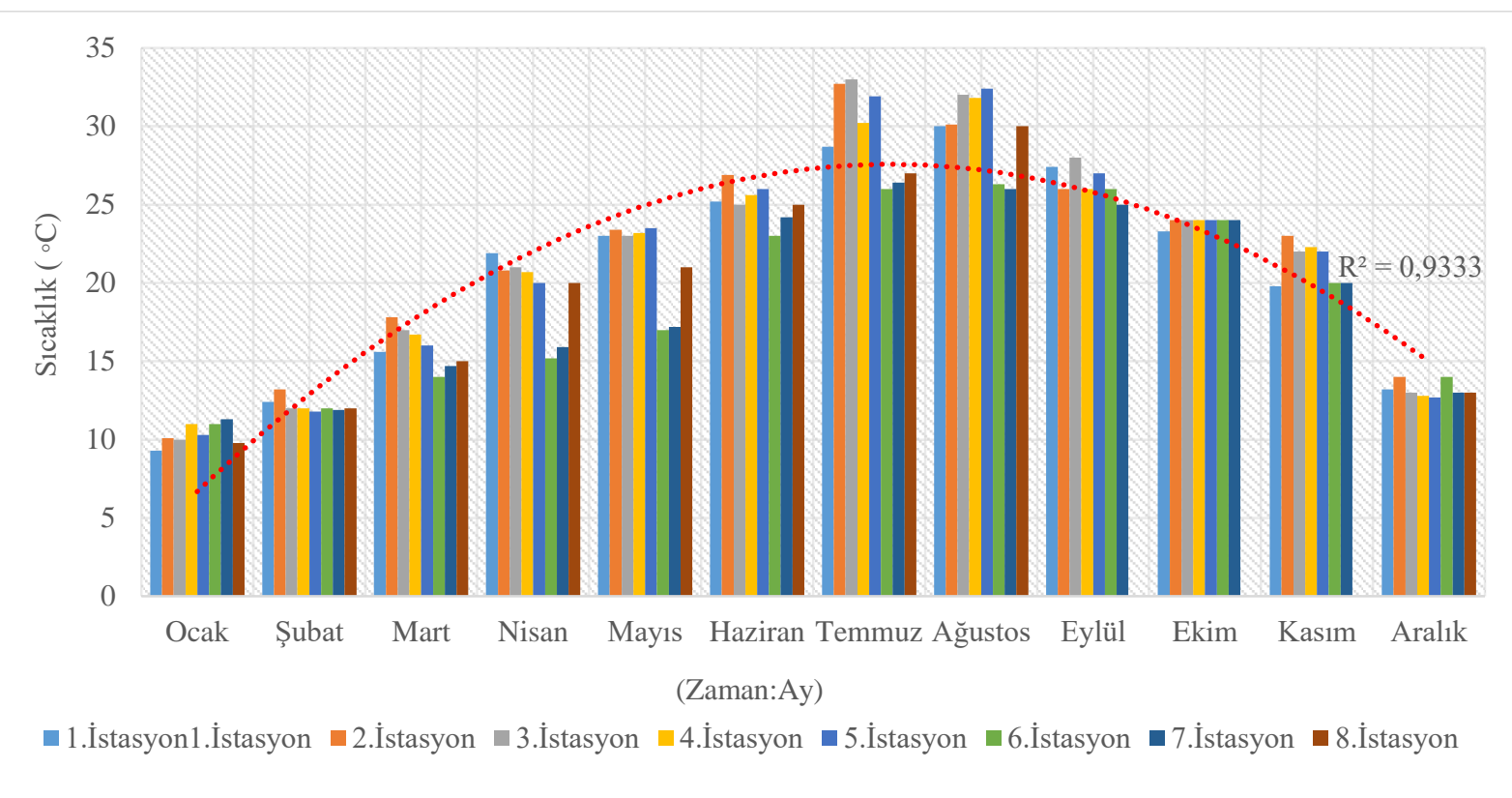

Şekil 4. Aylık sıcaklık değişimleri

Figure 4. Monthly temperature changes

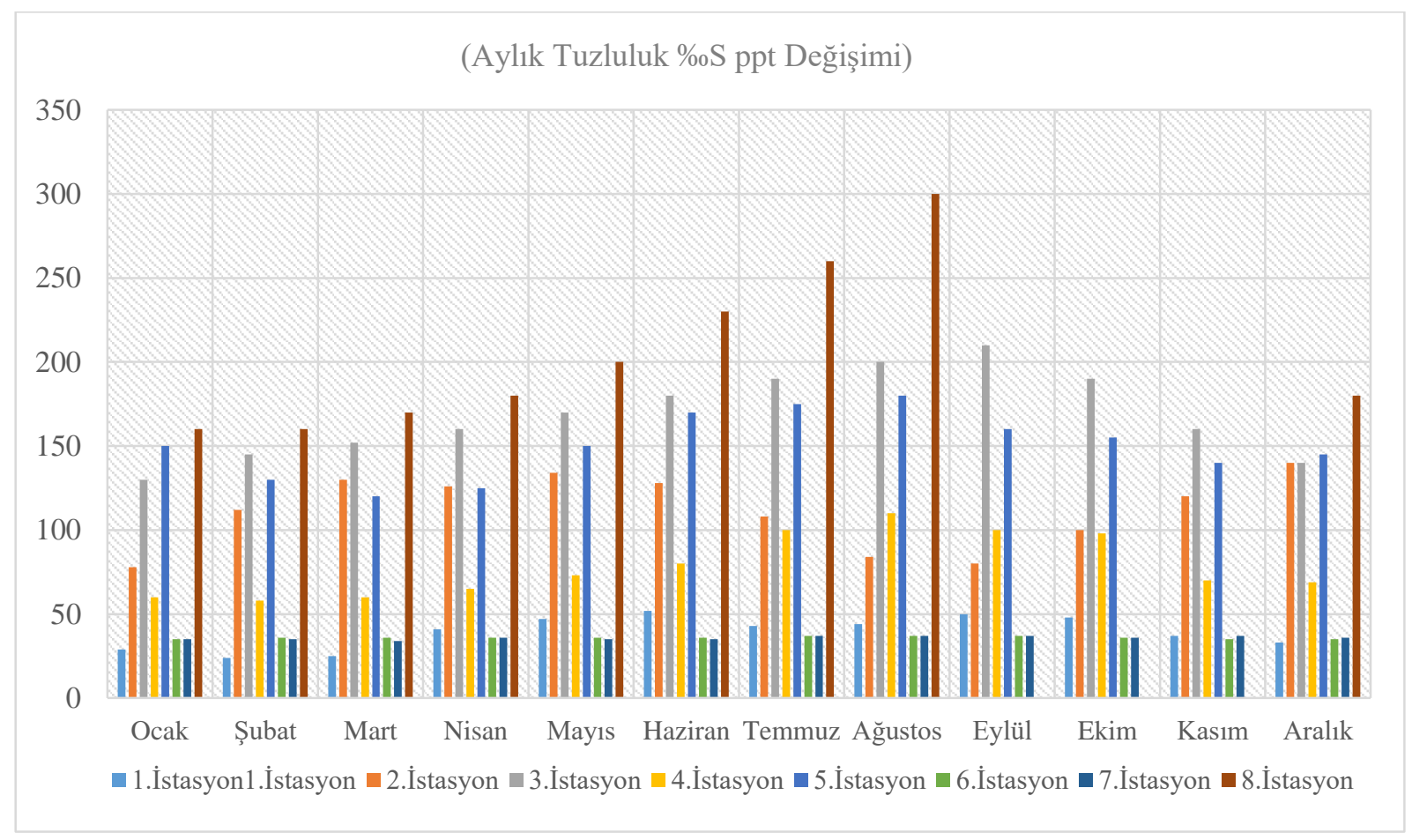

Şekil 5. Aylık tuzluluk değişimleri

Figure 5 . Monthly salinity changes 


\section{(Aylık Çözünmüș Oksijen Değişimleri (mg/L)}

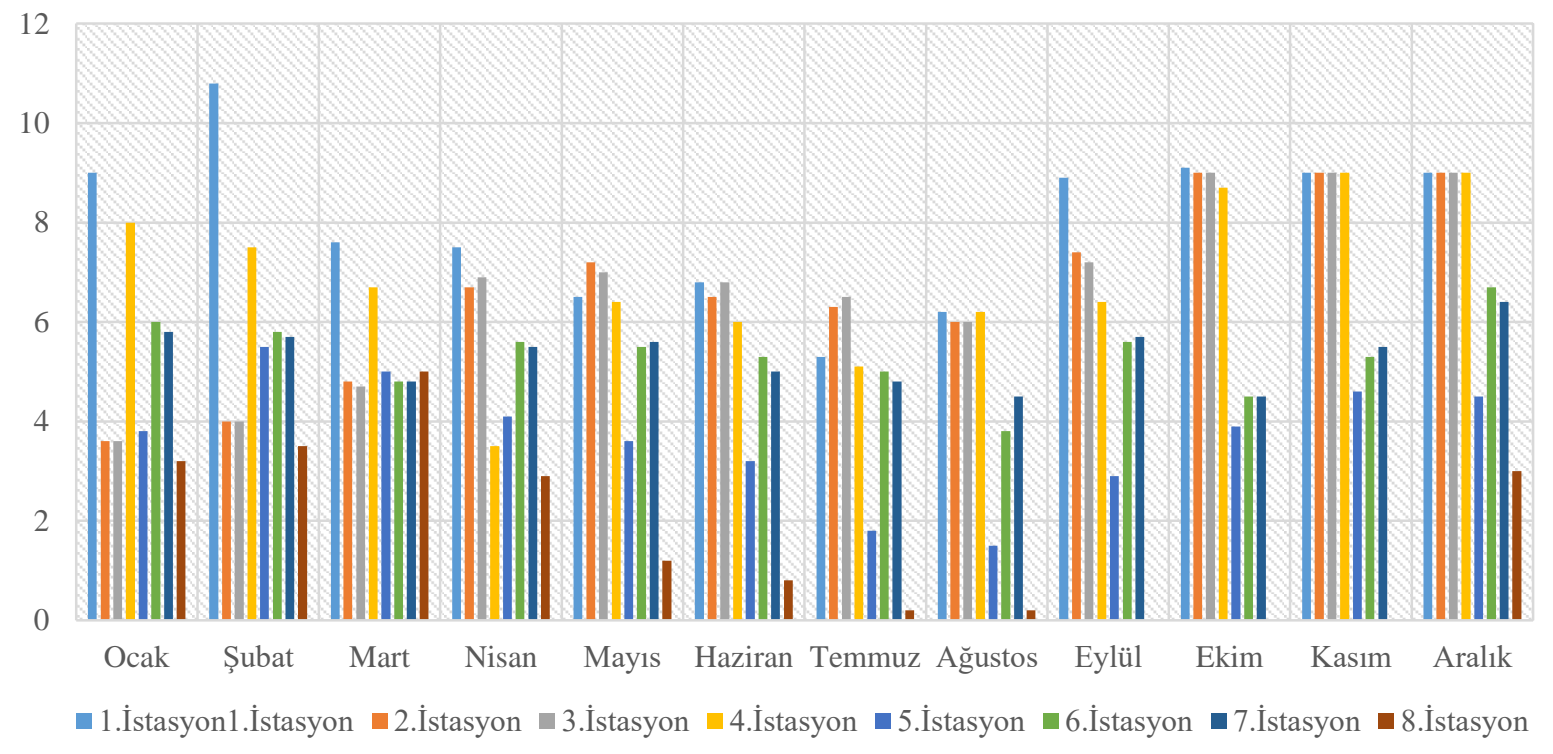

Şekil 6. Aylık oksijen değişimleri

Figure 6. Monthly oxygen changes

Tablo 3. 2015 yılı aylık dönemlerde ölçülen ve hesaplanan kimyasal parametrelerin örnekleme istasyonlarına göre değerleri

Table 3. The values of the chemical parameters measured and calculated for the 2015 monthly periods according to the sampling stations

\begin{tabular}{|c|c|c|c|c|c|c|c|c|}
\hline \multicolumn{9}{|c|}{$\begin{array}{c}\text { Zaman (2015 Yllı) } \\
\text { Aylar } \\
\text { Ocak:(Ock): Nisan: (Nsn), Haziran: (Hzn), Ağustos: (Ats), Eylül: (Eyl), } \\
\text { Kasım (Ksm), Arallk: (Ark) } \\
\text { Örnekleme istasyonları: (1), (2), (3), (4), (5), (6), (7), (8). }\end{array}$} \\
\hline Analitik Değişkenler & Ock & Nsn & $\mathrm{Hzn}$ & Ats & Eyl & Ksm & Ark & $\begin{array}{l}\text { Analiz } \\
\text { Yöntemi }\end{array}$ \\
\hline$\Sigma$ Fosfat $\left(\mathrm{PO}_{4}{ }^{-3} \mu \mathrm{g} / \mathrm{l}\right)$ & $\begin{array}{l}0,30(1) \\
0,36(2) \\
0,32^{3} \\
0,11^{4} \\
0,13^{(5)} \\
0,966^{6} \\
0,717 \\
0,01(8)\end{array}$ & $\begin{array}{l}0,37^{(1)} \\
0,28^{(2)} \\
0.18^{(3)} \\
0,15^{(4)} \\
0,15^{(5)} \\
1,2^{(6)} \\
1,0^{(7)} \\
0,01^{(8)}\end{array}$ & $\begin{array}{l}1,9(1) \\
2,3(2) \\
1,9(3) \\
0,14^{(4)} \\
0,96^{(5)} \\
2,6(6) \\
3,07 \\
0,01^{(8)}\end{array}$ & $\begin{array}{l}1,6^{(1)} \\
2,9^{2} \\
2,7^{3} \\
1,1^{4} \\
1,2^{(5)} \\
2,8(6) \\
2,3(7) \\
\star 8\end{array}$ & $\begin{array}{l}1,7^{(1)} \\
2,9^{(2)} \\
2,3^{(3)} \\
1,1^{4} \\
1,9^{(5)} \\
1,7^{(6)} \\
1,5^{(7)} \\
*(8)\end{array}$ & $\begin{array}{l}0,06^{(1)} \\
0,09(2) \\
0,1^{(3)} \\
0,07^{(4)} \\
1,6^{(5)} \\
0,2^{(6)} \\
0,17^{(7)} \\
*(8)\end{array}$ & $\begin{array}{l}0,08(6) \\
0,0877 \\
0,01(3) \\
0,06^{(4)} \\
0,96^{(5)} \\
0,016 \\
0,017 \\
0,018\end{array}$ & $\begin{array}{l}\text { APHA 4500- } \\
\mathrm{PO}_{4}\end{array}$ \\
\hline Nitrat $\left(\mathrm{NO}_{3}-\mu \mathrm{g} / \mathrm{l}\right)$ & $\begin{array}{l}0,67(1) \\
0,82(2) \\
0,933 \\
0,78(4) \\
0,83^{(5)} \\
0,62(6) \\
0,647 \\
0,008\end{array}$ & $\begin{array}{l}0,27^{(1)} \\
0,66^{(2)} \\
0,74^{(3)} \\
0,57^{(4)} \\
0,51^{(5)} \\
\left.0,92^{(}\right) \\
0,96^{(7)} \\
0,00^{(8)}\end{array}$ & $\begin{array}{l}0,36^{(1)} \\
0,68(2) \\
0,67(3) \\
0,577^{4} \\
0,61(5) \\
1,26 \\
1,27 \\
* 8\end{array}$ & $\begin{array}{l}0,67(1) \\
0,84^{(2)} \\
0,96(3) \\
0,78^{(4)} \\
0,93^{(5)} \\
0,996 \\
0,977^{(7)} \\
* \text { (8) }\end{array}$ & $\begin{array}{l}0,67(1) \\
0,84^{(2)} \\
0,84(3) \\
0,48(4) \\
0,63(5) \\
0,17(6) \\
0,197 \\
* \text { (8) }\end{array}$ & $\begin{array}{l}0,47(1) \\
0,34(2) \\
0,46(3) \\
0,28(4) \\
0,53^{(5)} \\
0,13(6) \\
0,13(7) \\
* \text { (8) }\end{array}$ & $\begin{array}{l}0,48(1) \\
0,23(2) \\
0,288^{(3)} \\
0,184 \\
0,96^{(5)} \\
0,111^{(6)} \\
0,12^{7} \\
0,00^{8}\end{array}$ & $\begin{array}{l}\text { APHA 4500- } \\
\mathrm{NO}_{3}\end{array}$ \\
\hline Nitrit $\left(\mathrm{NO}_{2}{ }^{-} \mu \mathrm{g} / \mathrm{l}\right)$ & $\begin{array}{l}0,06^{(1)} \\
0,46^{(2)} \\
1,10^{3} \\
1,88^{4} \\
1,34^{(5)} \\
0,07(6) \\
0,05(7) \\
0,01^{(8)}\end{array}$ & $\begin{array}{l}0,72^{(1)} \\
6,63^{(2)} \\
7.00^{(3)} \\
1,56^{(4)} \\
1,1^{(5)} \\
0,13^{(6)} \\
0,11^{(7)} \\
0,00^{(8)}\end{array}$ & 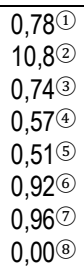 & $\begin{array}{l}10,4^{(1)} \\
16,8^{(2)} \\
15,9(3) \\
1,34^{(4)} \\
1,01(5) \\
0,07^{(6} \\
0,07(7) \\
* 8\end{array}$ & $\begin{array}{l}8,9^{(1)} \\
11,8^{(2)} \\
11,5^{(3)} \\
1,03^{(4)} \\
0,98^{(5)} \\
0,04^{(6)} \\
0,05^{(7)} \\
* 8\end{array}$ & $\begin{array}{l}2,9^{(1)} \\
9,9^{2} \\
11,5^{(3)} \\
1,1^{(4)} \\
0,98^{(5)} \\
0,04^{(6)} \\
0,05^{(7)} \\
* 8\end{array}$ & $\begin{array}{l}1,4^{(1)} \\
6,5(2) \\
11,5^{(3)} \\
0,78(4) \\
0,98(5) \\
0,04(6) \\
0,04(7) \\
*(8)\end{array}$ & $\begin{array}{l}\text { APHA 4500- } \\
\mathrm{NO}_{2}\end{array}$ \\
\hline
\end{tabular}




\begin{tabular}{|c|c|c|c|c|c|c|c|c|}
\hline $\begin{array}{l}\text { Amonyak }\left(\mathrm{NH}_{4}\right. \\
+\mu \mathrm{g} / \mathrm{l})\end{array}$ & $\begin{array}{l}0,33^{(1} \\
0,35^{(2)} \\
0,33^{(3} \\
0,36^{(4)} \\
0,57^{(5)} \\
0,67^{(6)} \\
0,70^{(7)} \\
0,01^{(8}\end{array}$ & $\begin{array}{l}0,08(1) \\
7,4^{(2)} \\
7,1^{(3)} \\
3,1^{(4)} \\
2,98(5) \\
0,07^{(6)} \\
0,05^{(7)} \\
0,01^{(8)}\end{array}$ & $\begin{array}{l}0,06^{(1} \\
13,4^{(2)} \\
12,1^{(3)} \\
3,88^{(4)} \\
2,34^{(5)} \\
0,07^{(6)} \\
0,05^{(7)} \\
0,00^{(8)}\end{array}$ & $\begin{array}{l}1,89(1) \\
14,6(2) \\
15,1(3) \\
2,77^{(4)} \\
2,89(5) \\
0,16^{(6)} \\
0,15(7) \\
* 8\end{array}$ & $\begin{array}{l}1.9(1) \\
15,3^{(2)} \\
15,1^{(3)} \\
2,2^{(4)} \\
3,6(5) \\
0,07^{(6)} \\
0,05^{(7)} \\
* 8\end{array}$ & $\begin{array}{l}0,2(1) \\
10,8(2) \\
10,5^{(3)} \\
1,9(4) \\
2,93(5) \\
0,09(6) \\
0,07(7) \\
* 8\end{array}$ & $\begin{array}{l}0,24(1) \\
0,54^{(2)} \\
0,48(3) \\
0,78^{(4)} \\
0,93^{(5)} \\
0,99(6) \\
0,97(7) \\
* 8\end{array}$ & $\begin{array}{l}\text { APHA 4500- } \\
\mathrm{NH}_{3} \mathrm{H}\end{array}$ \\
\hline Sülfat $\left(\mathrm{SO}_{4}^{-2} \mathrm{mg} / \mathrm{L}\right)$ & $\begin{array}{l}1780^{(1)} \\
7480^{(2)} \\
7476^{(3)} \\
8812^{(4)} \\
9610^{(5)} \\
3400^{(6)} \\
3410^{(7)} \\
10000^{8}\end{array}$ & $\begin{array}{l}2360^{(1)} \\
7980^{(2)} \\
7996^{(3)} \\
8898^{(4)} \\
9780^{(5)} \\
3400^{(6)} \\
3410^{(7)} \\
10000^{(8)}\end{array}$ & $\begin{array}{l}3570^{(1)} \\
9800^{(2)} \\
9806^{(3)} \\
8812^{4} \\
9610^{(5)} \\
3400^{(6)} \\
3400^{(7)} \\
* 8\end{array}$ & $\begin{array}{l}3750^{11} \\
5774(2) \\
5800^{(3)} \\
6457^{(4)} \\
18900^{(5)} \\
3390^{(6)} \\
3391^{(7)} \\
1980^{8}\end{array}$ & $\begin{array}{l}3200^{(1)} \\
5230^{(2)} \\
5300^{(3)} \\
4000^{4} \\
7000^{(5)} \\
3200^{6} \\
3240^{(7)} \\
*_{(8)}\end{array}$ & $\begin{array}{l}2320 \text { (1) } \\
3960^{(2)} \\
4350^{(3)} \\
3400^{4} \\
5680^{(5)} \\
3200^{6} \\
3200^{7} \\
*_{8}\end{array}$ & $\begin{array}{l}16701 \\
4120(2) \\
4890^{(3)} \\
4300^{(4)} \\
6200^{(5)} \\
3230^{(6)} \\
3238(7) \\
*\end{array}$ & $\mathrm{APHA} \mathrm{SO}_{4}$ \\
\hline Chl. $a \mu g / l$ & $\begin{array}{l}0,04(1) \\
0,05^{(2)} \\
0,05^{(3)} \\
0,04^{(4)} \\
0,03^{(5)} \\
0,03^{(6)} \\
0,03(7) \\
0,08\end{array}$ & $\begin{array}{l}0,56^{(1)} \\
0,40^{(2)} \\
0,45^{(3)} \\
0,55^{(4)} \\
0,43^{(5)} \\
0,49(6) \\
0,41^{(7)} \\
0,08\end{array}$ & $\begin{array}{l}1,311 \\
3,4^{(2)} \\
3,5^{3} \\
1,94 \\
1,65 \\
0,96 \\
0,947 \\
0,18\end{array}$ & $\begin{array}{l}2,9(1) \\
2,5(2) \\
2,6(3) \\
2,3(4) \\
1,5^{5} \\
0,496 \\
0,417 \\
*\end{array}$ & $\begin{array}{l}1,7(1) \\
1,9(2) \\
2,1(3) \\
1,74 \\
0,98(5) \\
0,49(6) \\
0,4177 \\
*\end{array}$ & $\begin{array}{l}2,9(1) \\
2,5(2) \\
2,6(3) \\
2,3(4) \\
1,5(5) \\
0,49(6) \\
0,417 \\
*\end{array}$ & $\begin{array}{l}0,23^{(1)} \\
0,33^{(2)} \\
0,35^{(3)} \\
0,29^{(4)} \\
0,12^{(5)} \\
0,2^{(6)} \\
0,19(7) \\
0,0^{8}\end{array}$ & $\begin{array}{l}\text { APHA (EPA } \\
446.0 \text {, SM } \\
10200 \\
\text { H.2.b.) }\end{array}$ \\
\hline $\begin{array}{l}\text { Magnezyum } \quad(\mathrm{Mg} \\
\mathrm{mg} / \mathrm{l})\end{array}$ & $\begin{array}{l}1357^{1} 1 \\
5678^{(2)} \\
5700^{(3)} \\
3200^{4} \\
2700^{(5)} \\
1260^{(6)} \\
1270^{(7)} \\
3340^{8}\end{array}$ & $\begin{array}{l}1357^{11} \\
5678^{(2)} \\
5700^{(3)} \\
3200^{4} \\
2700^{(5)} \\
1260^{(6)} \\
1270^{(7)} \\
3340^{8}\end{array}$ & $\begin{array}{l}1290^{(1)} \\
4700^{(2)} \\
4760^{(3)} \\
2200^{4} \\
2700^{(5)} \\
1260^{(6)} \\
1210^{(7)} \\
3500^{8}\end{array}$ & $\begin{array}{l}1300^{(1)} \\
5200^{(2)} \\
5190^{(3)} \\
1980^{4} \\
1700^{(5)} \\
1100^{(6)} \\
111300^{(7)} \\
*_{8}\end{array}$ & $\begin{array}{l}1230^{(1)} \\
4560^{(2)} \\
4700^{(3)} \\
1470^{4} \\
1290^{(5)} \\
1160^{6} \\
1170^{\circ} \\
*_{8}\end{array}$ & $\begin{array}{l}1120 \text { (1) } \\
4100^{(2)} \\
4190(3) \\
1200^{4} \\
1000^{5} \\
1260^{6} \\
12707 \\
*_{8}\end{array}$ & $\begin{array}{l}1190^{(1)} \\
2890^{(2)} \\
2800^{(3)} \\
1900^{(4)} \\
1070^{(5)} \\
1160^{(6)} \\
1100^{7} \\
{ }^{*} 8\end{array}$ & $\begin{array}{l}\text { TS EN ISO } \\
11885\end{array}$ \\
\hline
\end{tabular}

* Ölçüm yapılamadı: Havuzların yüksek tuzlulukta ( 300 ppt) veya tuz hasadından dolayı boş olması

\section{TARTIŞMA VE SONUÇ}

Kıyısal deniz tuzlalarında ekosistemi etkileyen en önemli abiyotik etken tuz yoğunluğudur. Ekosistemi oluşturan tuz üretim havuzlarındaki tuz yoğunluğu, yalnızca biyolojik bileşenleri kontrol etmekle kalmaz, aynı zamanda üretilecek olan tuzun kalitesi ve miktarını da belirler. Bu yüzden tuz yoğunluğunun kontrolü, birinci dereceden önemli tek etkendir (Dolapsakis et.al, 2005; Davis, 2006). Tuzluluk değeri bakımından Çamaltı Tuzlası 4 ana kısma ayrıı.ı. 1. Soğuk su havuzları (35-70 ppt), 2. Depo (Sergen) Havuzları (70-130 ppt), 3. Sıcak su Havuzları (130-250 ppt), 4. Kristalizasyon Havuzları (250-290 ppt). Tüm bu havuzların sayısı 155 adet olup her yıl fiziki altyapı bakımından farklı kullanış şekillerinde olabilmektedir. Havuzlardaki tuz yoğunluğunun, üretim sürecine bağlı olarak dengede tutulması ve korunmasında, Çamaltı tuzlasının bulunduğu coğrafik bölgedeki yıllık meteorolojik değerler de önemlidir. Havuzlardaki yüksek veya düşük tuzluluk, su devir daimini sağlayan (10-20 ton/dakika) pompalarla dengelenmektedir. Bu sayede her bir tuz üretim havuzundaki tuz yoğunluğu istenilen yoğunlukta tutulabilmektedir (Davis ve Giordano, 1996). Kıyısal deniz tuzlalarında, sudaki kimyasal değerler büyük farklılıklar gösterebilmektedir. Bunun sebebi, meteorolojik etkenlere bağlı olarak, sistemde oluşan buharlaşma $\left(23-24 \mathrm{~cm} / \mathrm{m}^{2}\right)$ sonucu, su takviyesi yapılmasıyla sürekli olarak 10-20 ton/dakika suyun hareket halinde olmasıdır. Bu sebeple $700 \mu \mathrm{M}$ ' ye kadar amonyum ve $40 \mu \mathrm{M}$ den fazla nitrat değerleri de tespit edilebilmektedir (Du Toit, 2001). Tuz üretiminin başladığı Nisan ayından, tuzun elde edildiği Eylül ayına kadar ekosistemde buharlaşmaya bağlı olarak sürekli bir su devir daiminin oluşu, biyotik faktörleri de oldukça değişken kılmaktadır.

Çamaltı tuzlası ekosisteminde takson sayısı bakımından ilk sırada yer alan Bacillariophyceae sınıfından Navicula sp. hâkim tür olarak gözükmekle beraber, Çamaltı tuzlasına has su devir daiminden dolayı, aslında sadece 1. ve 2. istasyonlarda mevcut bulunan bir takson olarak tespit edilmiştir. Bu istasyonlardan, tuzluluğu daha yüksek olan sahalara suyun sürekli, dakikada 10-20 ton pompalanmasindan dolayı Navicula sp. rastlanmamıştır. Çamaltı tuzlası sulak alanında sistemin dinamiklerini etkileyen abiyotik ve biyotik özelliklere bakıldığı en yaygın olarak bulunan alg türünün Chlorophyceae sınıfından $(\% 24,13) 7$ taksondan biri olan Dunaliella sp. olduğu tespit edilmiştir. Cyanophyceae sınıfı $(\% 13,79) 4$ takson ile yaygın olarak ekosistemde bulunmaktadır. Phaeophyceae sınifindan $(\% 10,34)$, Çamaltı tuzlasının kıyısal alanında 3 takson tespit edilmiştir.6. ve 7. İstasyon alanlarından deniz suyu çekilmesine rağmen ekosistemin içerisindeki yüksek tuz yoğunluğundan dolayı Phaeophyceae ve Monocots sinifi alglerine rastlanmamıştır. Rhodophyceae sınıfı algleri 3 takson $(\% 10,34)$ ile tespit edilmiştir. Bu taksonlardan sadece Laurencia papillosa ekosistemin içerisinde tuzluluğun 50-100 ppt olduğu alanlarda rastlanmışıı. Gracilaria sp., Hypnea sp. Ulva sp. ve Enteromorpha sp. makro algleri Çamaltı tuzlasının kıyısal deniz ekosisteminde tespit edilmiştir. Enteromorpha sp. Ocak-Mayıs 
aylarında daha çok dağılım göstermektedir. Ancak Ulva sp. deniz suyundaki sıcaklık ve besin tuzlarının artışından dolayı yoğun miktarda bulunmaktadır. Bu sebeple de Çamaltı tuzlası kıyısal zonunda Mayıs ve Haziran aylarında kokuşmaya sebep olmaktadır.

Tuzlanın bulunduğu coğrafik bölgede endüstriyel ve kentsel oluşumların varlığı da suyun kalitesinde etken olabilmektedir. Çamaltı tuzlasından alınan su numunelerinde fiziksel ve kimyasal parametre analizi yapılarak Su Kirliliği Kontrol Yönetmeliği'ndeki (Anonim, 2004; 2016) kıta içi su kaynaklarının sınıflarına göre kalite ölçütleri ve suyun bazı parametrelere göre kalite sınıfları ortaya konulmaya çalışımıştır. Tablo 4'teki değerlendirmeye bakıldığında, Çamaltı tuzlasının; sıcaklık, pH, nitrat ve toplam fosfor bakımından I. sınıf. Yalnız Temmuz, Ağustos aylarında ekosistemde göç eden Flamingo kuşlarının sayısının artmasına ve dışkılamaya bağlı olduğu düşünülen fosfor ve sülfat artışı tespit edilmiştir. Bu bakımından da sülfat ve fosfor için IV. sınıf su kalitesine de girmektedir. Çözünmüş oksijen bakımından II. sınıf su kalitesine sahip olduğu belirlenmiştir.

Tablo 4. T.C. Su Kirliliği Kontrol Yönetmenliği Kıta İçi Su Kaynaklarının Sınıflarına Göre ölçütleri (Anonim 2004; 2016)

Table 4. Republic of Turkey Water Pollution Control Directive Criteria for Classes of Inland Water Resources (Anonymous 2004;2016)

\begin{tabular}{|c|c|c|c|c|c|}
\hline \multicolumn{6}{|c|}{ Su Kirliliği Kontrol Yönetmenliği Kıta İçi Su Kaynaklarının Sınıflarına Göre Ölçütleri } \\
\hline \multirow{2}{*}{$\begin{array}{l}\text { Su Kalitesi Değişkenleri } \\
\text { Fiziksel ve inorganik- } \\
\text { kimyasal değişkenler }\end{array}$} & \multicolumn{5}{|c|}{ Su Kalitesi Sınıfı } \\
\hline & I. & II. & III. & IV. & $\begin{array}{l}\text { Çamaltı Tuzlası } \\
\text { Değerleri }\end{array}$ \\
\hline Sıcaklık $\left({ }^{\circ} \mathrm{C}\right)$ & 25 & 25 & 30 & $>30$ & 19,9 \\
\hline $\mathrm{pH}$ & $6,5-8,5$ & $6,5-8,6$ & $6-9$ & $>9$ & 7,76 \\
\hline Çözünmüş oksijen (mg O/L) & 8 & 6 & 3 & $>3$ & 5,51 \\
\hline Sülfat iyonu ( $\left.\mathrm{mg} \mathrm{SO}_{4}=/ \mathrm{L}\right)$ & 200 & 200 & 400 & $>400$ & 5300 \\
\hline $\begin{array}{l}\text { Amonyum azotu (mg } \mathrm{NH}_{4}{ }^{+}- \\
\mathrm{N} / \mathrm{L} \text { ) }\end{array}$ & 0,2 & 1 & 2 & $>2$ & $0,70-5,46$ \\
\hline Nitrat azotu (mg NO$\left.{ }^{-}-\mathrm{N} / \mathrm{L}\right)$ & 5 & 10 & 20 & $>20$ & $0,33-1,65$ \\
\hline Toplam fosfor (mg P/L) & 0,02 & 0,16 & 0,65 & $>0,65$ & $0,15-15.07$ \\
\hline
\end{tabular}

Çamaltı tuzlası ekosistemi; T.C. Su Kirliliği Kontrol Yönetmenliği Göller, Göletler, Bataklıklar ve Baraj Haznelerinin Ötrifikasyon Kontrolü Sınır Değerleri olan pH, çözünmüş oksijen, toplam fosfor ve Klorofil-a bakımından "Ötrofikasyon kontrolü sınır değerleri” içerisinde yer almaktadır.

Yalnız özellikle Temmuz, Ağustos aylarında göçmen flamingo kuşlarının sayısının artışından dolayı olduğu düşünülen sudaki kimyasal değerlerde geçici bir artış gözlenmiştir. Tablo 6'daki değerlendirmeye bakıldığında İzmir Çamaltı tuzlası fosfat bakımından yüksek mezotrofi ile ötrof seviyede; nitrat bakımından düşük mezotrofi ile ötrof seviyede; amonyak bakımından düşük mezotrofi ve ötrof seviyede; klorofil a değeri bakımından oligotrof ve ötrof seviyede görülmektedir.

Tablo 5. Göller, Göletler, Bataklıklar ve Baraj Haznelerinin Ötrofikasyon Kontrolü Sınır Değerleri (Anonim 2004; 2016)

Table 5. Eutrophication Control of Lakes, Ponds, Swamps and Dam Reservoirs Boundary Values (Anonymous 2004;2016)

\begin{tabular}{lllll}
\hline İstenilen Özellikler & $\begin{array}{l}\text { Doğal koruma } \\
\text { rekreasyon }\end{array}$ & alanı & $\begin{array}{l}\text { Cescitli kullanımlar için (Doğal Çamaltı Tuzlası Değerleri } \\
\text { olarak tuzlu, acı ve sodalı } \\
\text { göller dahil) }\end{array}$ & $\begin{array}{l}\text { (a) } \\
\text { pH }\end{array}$ \\
Oksijen $(\mathrm{mg} / \mathrm{L})$ & $6,5-8,5$ & $6-10,5$ & $6,9-8,1$ \\
Toplam fosfor $(\mathrm{mg} / \mathrm{L})$ & 7,5 & 5 & $5,3-7$ \\
Klorofil- $a(\mathrm{mg} / \mathrm{L})$ & 0,005 & 0,1 & $0,15-15.07$ \\
\hline
\end{tabular}


Tablo 6. Kıyısal bölgelere ait ötrifikasyona seviyeleri değerlendirmesi (Simboura et al., 2005)

Table 6. Assessment of eutrophication levels of coastal zones (Simboura et al., 2005)

\begin{tabular}{lllllc}
\hline Ötrifikasyona Değerleri & Oligotrof & $\begin{array}{l}\text { Çalışma } \\
\text { Püşük } \\
\text { Pezotrofi }\end{array}$ & $\begin{array}{l}\text { Yüksek } \\
\text { Mezotrofi }\end{array}$ & Ötrof & $\begin{array}{c}\text { Şamalları } \\
\text { Çamaltı } \\
\text { Tuzlası }\end{array}$ \\
\hline $\mathrm{PO}_{4}-3(\mu \mathrm{M})$ & $<0,07$ & $0,07-0,14$ & $0,14-0,68$ & $>0,68$ & $0,15-15.07$ \\
$\mathrm{NO}_{3}-(\mu \mathrm{M})$ & $<0,062$ & $0,62-0,65$ & $0,65-1,19$ & $>1,19$ & $0,33-1,65$ \\
$\mathrm{NH}_{4}+(\mu \mathrm{M})$ & $<0,055$ & $0,55-1,05$ & $1,05-2,20$ & $>2,20$ & $0,70-5,46$ \\
$\mathrm{Chl} a(\mathrm{mg} / \mathrm{l})$ & $<0,10$ & $0,1-0,6$ & $0,6-2,21$ & $>2,21$ & $0,03-4,77$
\end{tabular}

Yang et.al., (2008) in belirtiği Çin Çevre Koruma Kurumunun göl ya da rezervuar yüzey sularının kalitesi standartlarına göre de Çamaltı tuzlası su kalitesi sıcaklık, pH, çözünmüş oksijen değerleri bakımından I. sınıf, Amonyum azotu III.-IV. sınıf, nitrat azotu, fosfor ve klorofil a bakımından IV.-V. sınıf sular kapsamındadır. Ötrofikasyonlu sulardaki N ve $P$ değerleri bakımından fosfor açısından orta derecede ötrofik; azot bakımından oligotrofik sular kapsamındadır.

Tablo 7. Göl ya da rezervuar yüzey sularının kalitesi (Yang et.al., 2008)

Table 7. The quality of surface water on lake or reservoir waters (Yang et.al., 2008)

\begin{tabular}{|c|c|c|c|c|c|c|}
\hline \multirow{2}{*}{$\begin{array}{l}\text { Su Kalitesi } \\
\text { Değişkenleri }\end{array}$} & \multicolumn{6}{|l|}{ Su Kalitesi Sınıfı } \\
\hline & I. & II. & III. & IV. & v. & $\begin{array}{l}\text { Çamaltı } \\
\text { Tuzlası } \\
\text { Değerleri }\end{array}$ \\
\hline Sicaklık $\left({ }^{\circ} \mathrm{C}\right)$ & \multicolumn{5}{|c|}{ Haftalık en fazla artış 1 ve düşüş $\leq 2$} & $10,3-29,8$ \\
\hline $\mathrm{pH}$ & \multicolumn{5}{|l|}{$6-9$} & $6,9-8,1$ \\
\hline $\begin{array}{l}\text { Çözünmüş oksijen } \\
\left(\mathrm{mg} \mathrm{O}_{2} / \mathrm{L}\right)\end{array}$ & Saturasyon $\geq 90 \%$ & $\geq 6$ & $\geq 5$ & $\geq 3$ & $\geq 2$ & $5,3-7$ \\
\hline $\begin{array}{l}\text { Amonyum azotu } \\
\left(\mathrm{mg} \mathrm{NH}_{4}{ }^{+}-\mathrm{N} / \mathrm{L}\right)\end{array}$ & $\leq 0.15$ & $\leq 0.5$ & $\leq 1.0$ & $\leq 1.5$ & $\leq 2.0$ & $0,70-5,46$ \\
\hline $\begin{array}{l}\text { Nitrat azotu (mg } \\
\left.\mathrm{NO}_{3}-\mathrm{N} / \mathrm{L}\right)\end{array}$ & $\leq 0.06$ & $\leq 0.1$ & $\leq 0.15$ & $\leq 1.0$ & $>1.0$ & $0,33-1,65$ \\
\hline $\begin{array}{l}\text { Toplam fosfor (mg } \\
\text { P/L) }\end{array}$ & $\leq 0.01$ & $\leq 0.025$ & $\leq 0.05$ & $\leq 0.1$ & $\leq 0.2$ & $0,15-15.07$ \\
\hline Klorofil- a (mg/L) & $\leq 0.001$ & $\leq 0.004$ & $\leq 0.01$ & $\leq 0.03$ & $\leq 0.065$ & $0,03-4,77$ \\
\hline \multicolumn{7}{|c|}{ Ötrofikasyonlu sulardaki N ve P değerleri } \\
\hline Parametre & Oligotrofik & $\begin{array}{l}\text { Orta Derecede } \\
\text { Ötrofik }\end{array}$ & Ötrofik & Hiperötrofik & \multicolumn{2}{|c|}{ Çamaltı Tuzlası Değerleri } \\
\hline$\Sigma P(\mu \mathrm{g} / \mathrm{L})$ & $5 \sim 10$ & $10 \sim 30$ & $30 \sim 100$ & $>100$ & \multicolumn{2}{|c|}{$0,15-15.07$} \\
\hline$\Sigma N(\mu \mathrm{g} / \mathrm{L}$ & $250 \sim 600$ & $500 \sim 1100$ & $1000 \sim 2000$ & $>2000$ & \multicolumn{2}{|c|}{$0,33-1,65$} \\
\hline
\end{tabular}


Çamaltı tuzlası İmir körfezinde insan müdahalesiyle tuz üretmek amacıyla oluşturulmuş bir sulak alandır. Tuz üretiminin gereği olarak akışkan bir su rejimine sahiptir. Bu özelliğinden dolayı gerek yıllık meteorolojik eğişimler gerekse üretim süreciyle ilgili değişimlerden dolayı her yıl biyotik ve abiyotik özellikler bakımından farkıııklar gösterebilmektedir. Çalışmada 2015 yılına ait alg türlerinin dağılımı ortaya konulmaya çalışıımıştır. Elde edilen veriler kapsamında Çamaltı tuzlasının abiyotik etkenlere bağlı olarak en yaygın bulunan alg türünün Cyanophyta grubundan Dunaliella spp. olduğu tespit edilmiştir. Geniş tuzluluk aralıklarına dayanıklı olan Dunaliella mikroalgleri ekosistemdeki farklı ve yoğun tuzluluk alanlarında dağılım gösterebilmektedir. 154 üretim havuzundan ancak 25 âdetinde tuzluluk 50 ppt, diğer 104 havuzda 50-300 ppt. tuzluluk değerlerinin olduğu bir sulak alanda diğer alg türleri yaygın olarak bulunamamaktadır. Mevsimsel olarak da her ay ekosistemde bulunan bir mikroalgdir. Ekosistemin kıyısa zonasyonunda her mevsim bulunan alg olarak Cystoseria türü yaygındır. Enteromorpha, Ulva ve Gracillaria türleri de kıyısal alanda dağılım gösteren alglerdir. Çamaltı tuzlası insan yapımı bir sulak alan olarak Cyanophyceae sınıfına ait 4, Chlorophyceae sınıfına ait 7, Bacillariophyceae 11 takson, Phaophyceae sınıfına ait 3 takson, Rhodophyceae sınıfına ait 3 takson ve Monocots sınıfına ait 1 takson olmak üzere toplam 29 takson ile sürekli değişken yapısıyla dinamik bir ekosistemdir. Bu çalışmayla ülkemizin en büyük tuzlası olan İmir Çamaltı tuzlasında dağılım gösteren alg türleri araştırımış olup, Türkiye tuzlalarındaki algler hakkındaki bilgilere katkı yapılması amaçlanmıştır. Çalışma sonucunda elde edilen tür sayısı az olmakla birlikte, tespit edilen türlerin tuzladan ilk defa kayıt ediliyor olması, konu hakkındaki bilgi boşluğunun doldurulmasına katkı yapıldığını göstermektedir. Ülkedeki tuzlu ekosistemler genelinde yapılacak biyoçeşitlilik çalışmalarıyla, biyolojik zenginliğimiz ortaya çıkarılabilecek, tespit edilen türlerin korunması, akuakültürde ve sanayide değerlendirilmesi yönünde adımlar atılabilecektir.

\section{KAYNAKÇA}

Anonim (2004). Su Kirliliği ve Kontrolü Yönetmeliği, 31 Aralık 2004 tarihli Resmî Gazete, No:25687. Alıntılanma adresi: http://www.resmigazete.gov.tr/eskiler/2004/12/Su\%20Kirlili\%C4\%9Fi\%20 ekleri.htm (1.09.2017)

Anonim (2016). Su Kirliliği kontrolü yönetmeliği. Alıntılanma adresi: http://www.mevzuat. gov.tr/Metin.Aspx? Mevzuat Kod=7.5.7221\&sourceXmISearch=\&Mevzuatlliski=0. (18.09.2016).

APHA (1992). Standarts Methods for the Examination of Water and Wastewater. American Public Health Association 18 th. Edition, (Eds: Arnold E. Greenberg, Lenore S. Clesceri, Andrew D. Eaton, Marry Ann H. Franson) Washington, D.C. ISBN: 0-875553-207-1

Ak, İ. (2008). Türkiye'de Farklı Tuz Göllerinden İzole Edilen Dunaliella viridis' de Büyüme Koşullarının ve Karotenoid Birikiminin Araştırıması Çanakkale 18 Mart Üniversitesi Fen Bilimleri Enstitüsü, Doktora tezi Çanakkale.

Arora, M., Anıl, C.A., Leliaert, F., Delany, J. \& Mesbahi, E. (2013). Tetraselmis indica (Chlorodendrophyceae, Chlorophyta), a new species isolated from salt pans in Goa, India. European Journal of Phycology, 48(1):61-78. doi: 10.1080/09670262.2013.768357

Algaebase. (2017). Listing the World's Algae. Alıntılanma adresi: http://www.algaebase.org/search/commonnames (29.05.2017)

Bourrelley, P. (1968). Les Algues d'eau douce. Initiation á la systématique.Tome 2: Les Algues jaunes et brunes. Chrysophycées, Phéophycées, Xanthophycées et Diatomées. Paris, Boubée éd., 438 p. France.

Bourrelley, P. (1970). Les Algues d'eau douce. Initiation á la systématique. Tome 3: Les Algues bleues et rouges. Les Eugléniens, Péridiniens et Cryptomonadines. Paris, Boubée éd., 512 p. France.

Bourrelly, P. \& A. Couté. (1991). Desmidiées de Madagascar (Chlorophyta, Zygophyceae), Bibliotheca Phycologica, Band 86, 348 p. France.

Borowitzka M.A. (1997). Microalgae for aquaculture: opportunities and constraints. Journal of Applied Phycology. 9:393-401. doi: 10.1023/A:1007921728300

Cheng L. (1991). Proceedings of the International Symposium on Biotechnology of Salt Ponds, Tanggu, Tianjin, P.R. China, L. Cheng (ed.), Proceedings of the International Symposium on Biotechnology of Salt Ponds 18-21 September 1990. (283 pp.), Salt Research Institute, Ministry of Light Industry, Tianjin, China.

Davis, J.S. \& Giordano, M. (1996). Biological and physical events involved in the origin, effects, and control of organic matter in solar saltworks.

International Journal of Salt Lake Research 4:335-347. doi: 10.1007/BF01999117

Du Toit, S.R. (2001). Biological management of South African solar saltworks. $\mathrm{PhD}$ thesis, University of Port Elizabeth, $260 \mathrm{pg}$.

Dolapsakis N., Tafas T., Abatzopoulos T., Ziller S. \& Economou-Amilli A. (2005). Abundance and growth response of microalgae at Megalon Embolon solar saltworks in northern Greece: An aquaculture prospect, Journal of Applied Phycology, 17:39-49.doi: 10.1007/s10811-005-5553-0

Davis J.S. (2006). Biological and physical management information for commercial solar saltworks, In: Ecological importance of solar saltworks, Lekkas T.D. and Korovessis N.A.(eds.), Proceedings of the 1st International Conference on the Ecological Importance of Solar Saltworks (CEISSA 06), Santorini Island, Greece, 20-22 October 2006, GlobalNEST, Athens. doi: 10.1007/BF01999117

EN ISO 11885 (2009). TSE, Su kalitesi- Seçilmiş elementlerin tümevarımla olarak bağlanmış plazma optik emisyon spektrometresiyle (ICP-OES) tayini, EN ISO 11885:2009. Alıntılanma adresi:https://intweb.tse.org.tr/standard/standard/Standard.aspx?(1.01.2 015)

Google Earth (2017). Alıntılanma adresi: https://www.google.com/int/tr/earth/ (5.06.2017).

Hof, T. \& Frémy, P. (1933). On Myxophyceae living in Strong brines. Recueil Travaux Botaniques Netherlands 30:140-162.

Hecky; E.R. \& Kilham, P. (1973). Diatoms in Alkaline, Saline Lakes: Ecology and Geochemical Implications, Limnology and Oceanography, January 1973, 18(1). doi: 10.4319/lo.1973.18.1.0053

IOC-UNESCO. (2017). Taxonomic Reference List of Harmful Micro Algae, Alıntılanma adresi: http://www.marinespecies.org/hab/index.php (01.06.2017).

Koray, T., Yurga, L. \& Çolak-Sabancı. (2007). Türkiye Denizleri Mikroplankton (=Protista) Türlerinin Kontrol Listesi ve Tür Tayin Atlası. Proje No: TBAG2239 (102T174). 154 pp.

Korovessis N.A. \& Lekkas T.D. (2000). Saltworks: Preserving Saline Coastal Ecosystems. Post Conference Symposium Proceedings. 6th Conference on Environmental Science and Technology, Pythagorian, Samos, 1 September 1999, 95 pp. Global Nest, Athens.

LPSN. (2017). List of Prokaryotic names with Standing in Nomenclature, Alıntılanma adresi: http://www.bacterio.net also see http://www.microbiologyonline.org.uk/home (23.05.2017). 
MGM. (2015). Devlet Meteoroloji Genel Müdürlüğü. Alıntılanma adresi: http://www.mgm.gov.tr/veridegerlendirme/il-ve-ilceleristatistik.aspx?m=izmir\#sfb (23.05.2016)

Nübel, U., Garcia-Pichel, F. \& Muyzer., G. (2000). The halotolerance and phylogeny of cyanobacteria with tightly coiled trichomes (Spirulina Turpin) and the description of Halospirulina tapeticola gen. nov., sp. nov. International Journal of Systematic Evolutionary Microbiology 50:12651277. doi:10.1099/ijsem.0.002357

Nagasathya, A. \& Thajuddin, N. (2008). Cyanobacterial Diversity in the Hypersaline Environment of the Saltpans of Southeastren Coast of India Asian Journal of Plant Sciences 7(5): 473-478, ISSN: 1682-3974. doi:10.3923/ajps.2008.473.478

Oren, A. (2005). A hundred years of Dunaliella research: 1905-2005, Salina Systems, 1,2, doi:10.1186/1746-1448-1-2

Pritchard, D. (2010). Managing wetlands: Frameworks for Managing Wetlands of International Importance and other wetland sites. Ramsar Handbooks for the Wise use of Wetlands, $4^{\text {th }}$ Edition, Vol. 18. Ramsar Convention Secretariat, Gland, Switzerland. Alıntılanma adresi: http://www.ramsar.org (20.06. 2017)
Plankweb. (2017). Check-list of Turkish Seas Microplankton Alıntılanma adresi: http://plankweb. Check-list of Turkish Seas Microplankton (15.06.2017).

Simboura, N., Panayotidis, P. \& Papathanassiou, E. (2005). A synthesis of the biological quality elements for the implementation of the European Water Framework Directive in the Mediterranean ecoregion: The case of saronikos Gulf. Ecological Indicators 5:253-266. doi: 10.1016/j.ecolind.2005.03.006

UNEP. (2013). The Spanish saltworks areas, "Las Salinas", on the islands of Ibiza and Formentera at UNEP's World Conservation Monitoring Centre. Alıntılanma adresi: http://www.unepwcmc (10.06.2017)

Yang, X., Wu, X., Hao, H. \& He, Z. (2008). Mechanisms and assessment of water eutrophication, Journal of Zhejiang University SCIENCE $B$, 9(3):197-209, ISSN 1862-1783.

Yurga, L. (2015). Distribution of phytoplankton species in İzmir Bay for 15 years and its comparative statistical analysis. Ege Journal of Fisheries and Aquatic Sciences 32(1):25-30. doi: 10.12714/egejfas.2015.32.1.04

WoRMS. (2016). World Register Marine Species, Alıntılanma adresi: http://www.marinespecies.org/index.php (29.05.2017). 